\title{
La hegemonía cultural del glolugar: entre la relegación y la reivindicación local. \\ El caso de Valencia
}

\author{
Gil-Manuel Hernàndez i MarTí \\ Universitat de València \\ gil.hernandez@uv.es
}

\author{
Francisco TorRes PÉREZ \\ Universitat de València \\ francisco.torres@uv.es
}

Recibido: 29-05-2014

Aceptado: 18-02-2015

\section{Resumen}

El artículo tiene por objeto abordar cómo la hegemonía del glolugar, en tanto que figura paradigmática de los procesos urbanos neoliberales, ha implicado un determinado modelo de política cultural y de desarrollo urbano que hemos podido singularizar en el caso de la ciudad de Valencia y la Ciudad de las Artes y de las Ciencias. La hegemonía cultural del glolugar no se puede entender sin enmarcarla en una tendencia global como es la extensión del urbanismo neoliberal, en la que la ciudad es concebida como una entidad competitiva inmersa en un espacio global que promueve la mercantilización del espacio urbano y la mentalidad emprendedora en la gestión pública local. A partir del estudio del caso de Valencia, analizaremos la vinculación entre urbanismo neoliberal, la política cultural y el modelo de ciudad. Sin embargo, mostraremos como frente a las políticas neoliberales del glolugar se ha ido conformando desde los barrios populares algunas acciones socio-culturales para contrarrestar esta tendencia gentrificadora y para proponer alternativas culturales y de planificación urbana.

Palabras clave: glolugar, globalización, branding, precarización, Valencia. 


\title{
The Cultural Hegemony of the Global Places: Between Relegation and the Local Claim. The Case of Valencia
}

\begin{abstract}
This paper discusses how the hegemony of the global place (glolugar), the paradigmatic figure of the urban neoliberal processes, has implied a certain model of cultural policy and urban development. This model has been developed in the project of City of the Arts and of the Sciences, in Valencia City. The cultural hegemony of the glolugar cannot be understood without framing it in a global trend since it is the extension of the neoliberal urbanism. In this frame, the city is conceived as a competitive entity in a global space that promotes the commoditization of urban space and the entrepreneurial attitude in the local public management. From the analysis of the City of the Arts and of the Sciences, we will investigate the links between neoliberal urbanism, cultural politics and city model. Nevertheless, we will show how the struggles against these neoliberal policies of the glolugar there has been conforming in the popular neighborhoods some socio-cultural actions, to counteract this gentrifying trend and to propose an alternative culture and urban planning.
\end{abstract}

Keywords: Gloplace; Globalization; Branding; Precarious; Valencia.

\section{Referencia normalizada}

Hernàndez i Martí, Gil-Manuel y Francisco Torres Pérez (2015): “La hegemonía cultural del glolugar: entre la relegación y la reivindicación local. El caso de Valencia”, Política y Sociedad, 52 (1), pp. 53-73.

Sumario: 1. Introducción. 2. El glolugar, el urbanismo y la política cultural neoliberal. 3. El área Ciudad de las Artes y las Ciencias-Puerto Deportivo. El glolugar de Valencia. 4. La vida más allá del glolugar. Los barrios populares. 5. Iniciativas desde los barrios: la acción sociocultural alternativa. 6. Conclusiones. 7. Bibliografía. 


\section{Introducción}

Este artículo aborda la transformación de Valencia a partir de la creación y hegemonía de un glolugar, la Ciudad de las Artes y de las Ciencias, un proyecto urbanístico con decisivas consecuencias a nivel urbanístico y de política cultural. Al mismo tiempo, mostraremos como los barrios y actores sociales que han sido relegados por este proceso han articulado resistencias y respuestas socio-culturales al modelo de ciudad hegemónico hoy en crisis.

La hegemonía cultural y urbana del glolugar no se puede entender sin enmarcarla en la extensión del urbanismo neoliberal, hegemónico a nivel global. En el caso de Valencia, claro ejemplo de "estilo consumista de urbanización" (Harvey, 1989:12), el proyecto de ciudad neoliberal ha pivotado sobre los grandes proyectos y eventos, con la espectacular Ciudad de las Artes y de las Ciencias como mascarón de proa, y una expansión urbana que, servida por un "urbanismo a la carta" (Gaja, 2006), ha creado nuevos barrios y una nueva periferia de medio y de alto standing (Cucó, 2013). Todo ello, ofrecido con un cuidado marketing urbano basado en la exaltación de la vanguardia, la innovación y la globalidad. Vamos a poner Valencia, se decía, en el "mapa del mundo".

Como señalan entre otros Brenner y Theodore (2002), Díaz Orueta (2013) y Smith (1996), la ciudad neoliberal es concebida como una entidad competitiva inmersa en un espacio global que promueve el espacio urbano como mercancía, el ambiente favorable a los negocios y la mentalidad emprendedora a través de nuevas prácticas de la gestión pública. A partir de los años noventa, las agendas y políticas culturales urbanas se fueron reorientando para priorizar el crecimiento económico y la competencia entre ciudades mediante la espectacularización (Alcalá-Santaella et al., 2011; Harvey, 2013; Brenner y Theodore, 2002). En España este modelo se aplicó primero en las grandes áreas metropolitanas, Madrid y Barcelona, y en ciudades en fuerte declive industrial como Bilbao. Más tarde, le siguieron el resto de las grandes ciudades españolas, preocupadas por competir en el campo global de las nuevas ciudades-espectáculos.

Nuestra reflexión pretende vincular urbanismo neoliberal, política cultural y modelo de ciudad, utilizando como clave de bóveda el rol que el glolugar (Hernàndez, 2013), en nuestro caso la Ciudad de las Artes y de las Ciencias, tiene en el proceso. Entendemos que esta opción analítica muestra aspectos de interés y permite captar la unidad profunda entre esas distintas dimensiones -urbanismo, cultura e idea de ciudad- del proyecto neoliberal. Como base empírica, el texto se basa en algunos resultados del Proyecto "Metrópolis glocalizadas: el caso de Valencia. Espectacularización y precarización urbana en las ciudades medianas", CSO2009-10715, y del Proyecto "El sistema de la política cultural en España”, CSO2008-05910. Para nuestra exposición 
hemos utilizado, además del análisis documental y estadístico, entrevistas a informantes clave y diversos grupos de discusión realizados en los proyectos mencionados. ${ }^{1}$

$\mathrm{El}$ artículo se estructura en cuatro apartados. En primer lugar, se define el glolugar y su rol en el marco del urbanismo neoliberal. Se presenta, en segundo lugar, el área Ciudad de las Artes y Las Ciencias, su papel central como glolugar en el proyecto de la Valencia global tanto en lo urbanístico como en lo cultural. Esta hegemonía del glolugar ha implicado, en el caso de Valencia, la relegación de los barrios populares en el plano urbanístico, social y cultural. Abordamos, en tercer lugar, sus implicaciones en los casos de los barrios del Carme, Mercat y Cabanyal, representativos de otros espacios urbanos populares de la ciudad y, también, de las resistencias surgidas. En efecto, frente a las políticas neoliberales del glolugar, se ha ido conformando desde los barrios populares una serie de acciones socio-culturales desarrolladas por una red de asociaciones, grupos y colectivos, que abordamos en cuarto lugar. Estas respuestas, unas más profesionales y otras más críticas con dicho modelo, ahora en crisis, proponen iniciativas culturales distintas $\mathrm{y} / \mathrm{o}$ alternativas.

\section{El glolugar, el urbanismo y la política cultural neoliberal}

Los glolugares describen un espacio urbano híbrido que conjuga aspectos del lugar (incluso del lugar de memoria) y del no-lugar, sin ser ninguno de los dos en concreto. Los glolugares no son espacios ni política ni ideológicamente neutros. Por un lado se presentan como vectores del crecimiento económico y urbano propio del "urbanismo empresarial" (Harvey, 1989; Swyngedouw et al., 2002); por otro, sirven a un fin, a una determinada política cultural ligada a un relato neoliberal de la ciudad, a un proyecto de dominación, que implica, en última instancia, una reformulación simbólica de la identidad (Hernàndez, 2013). Al respecto se podrían citar las instalaciones de las Exposiciones Universales y de los Juegos Olímpicos, recintos como el Futuroscope de Poiters, el Museo Gugenheim de Bilbao y especialmente los vanguardistas espacios edificados en países de Golfo Pérsico, como Emiratos Árabes Unidos (Dubai), o las antiguas repúblicas ex-soviéticas muy ricas en recursos naturales, como Uzbekistán, Azerbayán y Kazajistán (Prieto, 2011).

Los glolugares implican áreas especiales preferentemente urbanas caracterizadas por una orientación eminentemente glocal, en la medida que concilian un carácter sin-

${ }^{1}$ En el primero de estos proyectos, sobre la Valencia glocalizada, se realizaron 34 entrevistas en profundidad a vecinos de cuatro barrios seleccionados y, a nivel de ciudad, 10 entrevistas a técnicos y profesionales y 8 grupos de discusión, 4 en 2011 y otros 4 en 2013. En el segundo proyecto, centrado en política cultural, se realizaron 22 entrevistas en profundidad, abarcando las esferas autonómica, provincial y local, a técnicos de cultura, responsables políticos, así como a agentes de sectores profesionales, asociativos y de industrias culturales. 
gular local con la explícita voluntad de proyección global, a través de su inserción mediática en las principales redes de ciudades globales (Sassen, 2001), ya sean de primer o segundo rango. Para acentuar su conexión mundial suelen concentrar elementos arquitectónicos impactantes, rompedores o con rasgos de ultramodernidad y vanguardia y buscan, a través del cultivo de la espectacularidad y la exhibición mundial, dotarse de singularidad y distintividad. El glolugar además, ocupa superficies considerables, en algunos casos en zonas urbanas nuevas y en otros en antiguas zonas degradadas o sin usos claros, que quedan así redefinidas, rediseñadas y reimaginadas en clave de modernidad cosmopolita. En el conjunto de la ciudad, los glolugares se presentan como islas de cosmopolitismo, elitista y neoliberal, en la medida en que tienden a subrayar dicho carácter en las ciudades que los acogen para de este modo facilitar su inserción simbólica en la red de ciudades globales. Esta circunstancia puede significar que la singularidad histórica y patrimonial de la ciudad en la que se ha asentado el glolugar pase a un segundo plano respecto a este último, a modo de complemento "pintoresco" o atrezzo local de lo novedoso, vanguardista y cosmopolita que representa el glolugar (Torres y Hernández, 2013; Prieto, 2013).

Con su despliegue en el tejido urbano, los glolugares aspiran a crear un efecto de punto de inflexión histórico en la trayectoria de la ciudad donde se ubican. Un glolugar presenta rasgos de los lugares de memoria, pero en vez de que el pasado actúe como referente histórico del presente, que es lo que sucede con los lugares clásicos, en este caso es el presente el que actúa como referente histórico para el futuro. El glolugar coloniza el imaginario local, redefiniéndolo, hasta el punto de desplazar a los hitos históricos de las narrativas locales y acabar ocupando el centro simbólico de la imagen de la ciudad.

En los relatos oficiales, los glolugares suelen ser presentados como factor de desarrollo económico, vía turismo y notoriedad mediática, y como potente revulsivo del orgullo local, un acicate para promover el sentimiento de pertenencia, mediante la constatación de una proyección destacada en lo global. A partir del advenimiento del glolugar, la ciudad "glolugarizada" se "brandifica", se convierte en una "ciudad-marca" que intentará cotizar al alza en el mercado mundial de ciudades emergentes o consagradas. Y en el caso de las ciudades emergentes, el glolugar las "pone en el mapa".

Los glolugares sirven para albergar grandes eventos urbanos, en los que se persigue la exaltación de la ciencia y la tecnología, la apelación a la cultura y el arte, la vocación de espectáculo (especialmente el deportivo), ocio y diversión, y su aspiración a convertirse en icono turístico y nuevo condensador de una identidad local redefinida por el propio impacto del glolugar. Por su capacidad de concentrar grandes eventos, grandes proyectos y grandes infraestructuras, los glolugares contribuyen a propiciar oportunidades de grandes negocios, que en no pocas ocasiones van ligados a situaciones de corrupción y nepotismo en las administraciones públicas que los promueven y que, frecuentemente, los financian.

Como espacios escenográficos de la opulencia, los glolugares se insertan en los circuitos globales de competitividad y mercantilización cultural, por lo que son sinónimo de 
crecimiento y cambio, y depende mucho de la arquitectura y la redefinición de antiguos paisajes urbanos más o menos degradados que contribuye a reinterpretar y recodificar. Por esta razón los glolugares también presentan rasgos de adaptabilidad y flexibilidad, en la medida que aspiran a ser referentes en el competitivo y brandificador mundo urbano del capitalismo tardío. Sin embargo, y debido a ello, los glolugares se ven obligados a redefinirse y a reinventarse continuamente, lo que a la postre les confiere fragilidad al poder quedar obsoletos o desplazados por glolugares más novedosos, espectaculares y dinámicos.

\section{El área Ciudad de las Artes y las Ciencias-Puerto Deportivo El glolugar de Valencia}

A partir de la segunda mitad de los años noventa el gobierno valenciano del Partido Popular se lanzó a redefinir los perfiles urbanísticos, culturales y turísticos de la ciudad de Valencia. En este proyecto, la Ciudad de las Artes y las Ciencias ha tenido un rol central y no sólo por sus enormes dimensiones. El complejo está ubicado en la desembocadura del antiguo lecho del río Turia, convertido desde los años ochenta en un gran jardín urbano, el Parque del Turia, que articula la ciudad de noroeste al sudeste. Construido entre 1993 y 2008, ocupa una superficie de 35 hectáreas y 1.800 metros de longitud y que, con su desarrollo, ha generado una transformación radical de todo el entorno adyacente y marcado la política de la ciudad. ${ }^{2}$

El complejo de la CAC consta de seis edificios, ${ }^{3}$ entre ellos el Palau de les Arts Reina Sofia, y dos puentes. Todas las construcciones, excepto el Oceanográfico, son obra de Santiago Calatrava y remiten al estilo espectacular, seudo-organicista y grandioso que caracteriza a este arquitecto estrella. En este marco futurista se han desarrollado grandes eventos globales muy mediáticos, festivales de música como el MTV Winters, eventos deportivos como el Masters ATP de Tenis, la Global Champions Tour Hípica (2009), certámenes informáticos como el Campus Party o el Encuentro Mundial de las Familias de 2006, presidido por el papa Benedicto XVI.

La hegemonía de la CAC y las dinámicas de todo tipo que un complejo de esas dimensiones genera han tenido un papel central en la gestión de la ciudad, tanto en el plano socio-urbano como en el de la política cultural. Respecto al primero, a un lado y

${ }^{2}$ La CAC está gestionada por la sociedad CACSA, con un $100 \%$ de capital público. No se sabe el coste real del complejo, aunque estimaciones paraoficiales lo sitúan en 1.300 millones de euros, un sobrecoste del $500 \%$ respecto al presupuesto inicial.

${ }^{3}$ Se tratan de L'Hemisfèric, donde se proyectan películas en formato IMAX y Laserium; el Museo de las Ciencias Príncipe Felipe, con L’Umbracle; El Oceanogràfic, un acuarium de más de 110.000 metros cuadrados y el Palau de les Arts Reina Sofía un auditorio múltiple de cuatro salas para ópera, danza y teatro. Posteriormente se añadió el edificio del Ágora, sin uso concretado. 
otro de la CAC, sobre antiguos terrenos industriales o de huerta, se han levantado dos nuevos barrios de medio y alto standing, el barrio de Penya-Roja y el barrio Ciutat de les Arts i les Ciències. Se trata de un modelo new build gentrification que se ha extendido a otros barrios y espacios urbanos surgidos en Valencia, a menudo "estimulado" por un gran proyecto urbanístico. ${ }^{4}$ Por otro lado, el complejo CAC ha generado una nueva centralidad sobre todo icónica, cultural y turística, pero también de servicios y centros comerciales. Además, cabría añadir las inversiones y actuaciones diversas en materia de red viaria, urbanización y ajardinamiento, así como en infraestructuras en general.

Más allá de estos impactos, la hegemonía de la CAC y sus lógicas subyacentes han tendido a la expansión, conforme se consolidaba el modelo. Para la celebración de la America's Cup en 2007 se remodeló el Puerto de la ciudad con la edificación de la Marina Real Juan Carlos I, con edificios vanguardistas como Veles e vents, puerto deportivo (Port America's Cup), instalaciones especializadas en regatas, una zona de ocio nocturno y un Puerto especializada en megayates de lujo (Valencia Superyacht Marina). En la misma zona, se acondicionó un circuito urbano para carreras de Fórmula 1 con una primera edición en 2008. Se pretendía transformar el puerto en un amarradero de cruceros de lujo y atraer a Valencia una selecta clientela de turistas, profesionales y ejecutivos de alto nivel. Otro sueño que se llevó la crisis. En todo caso, todo ello ha generado una completa transformación del frente marítimo norte y ha confirmado un glolugar más amplio, CAC-Puerto Deportivo (CAC-PD).

Además de su impacto socio-urbano, la política cultural autonómica valenciana y de la ciudad de Valencia ha pivotado alrededor de la CAC-PD y sus grandes eventos tanto por lo que hace al tipo de actos y manifestaciones, como por las prioridades de agenda que establece así como la cantidad de fondos públicos que consume. ${ }^{5}$ En el apartado de contenidos, lo glamouroso, vanguardista y cosmopolita son los valores en alza que se demandan a los nuevos "emprendedores culturales", se impone frente a lo propio y popular. Considérese, a nivel presupuestario, lo que supone mantener una

${ }^{4}$ Así "Nuevo Benicalap" y "Nuevo Campanar", en el eje de la avenida Corts Valencianes con el Palacio de Congresos de Foster y el nuevo Mestalla. En otros casos, estos barrios han surgido sin vinculación con los proyectos, como Sociopolis y Avenida Alfahuir, pero formando parte de su "narrativa": aprovechar el negocio que generaría ese vecindario acomodado, cosmopolita e interconectado que iba a atraer la Valencia global.

${ }^{5}$ La CAC SA se constituyó como sociedad en 1991 según el derecho privado pero con la Generalitat Valenciana como accionista único. Del presupuesto inicial de 308 millones de euros se pasó, con sucesivas ampliaciones de obras, a 1.300 millones. En 2012 CAC S.A incurrió en causa de disolución dadas las pérdidas acumuladas, la mitad de las cuales correspondía a una deuda evaluada en 765 millones de euros (Tudela, 2014). Por otro lado, la evolución de las partidas presupuestarias de cultura de la Generalitat Valenciana entre 2008 y 2012 demuestra que mientras las cuatro clásicas (libro, archivos y bibliotecas; artes plásticas y escénicas; promoción cultural y patrimonio cultural) oscilaban entre el $0,03 \%$ y $0,08 \%$ de los presupuestos públicos valencianos, la coordinación y ejecución de los grandes proyectos movilizaba entre el $0,12 \%$ y el $0,21 \%$ de los mismos (Hernández et al., 2014). 
compañía y una programación de ópera que, en algunas temporadas, ha rivalizado con el Real de Madrid o el Liceu de Barcelona. ${ }^{6}$

Debe subrayarse que el despliegue de la política cultural oficial articulada por los grandes proyectos y eventos presenta dos versiones que intentan contentar a diversos públicos. En primer lugar existe una "programación" orientada al consumo de un público masivo, popular y de alcance global, como conciertos de pop-rock, eventos informáticos y tecnológicos y espectáculos diversos, que atraen a visitantes y muchos vecinos de Valencia. Junto a ello, en segundo lugar, se desarrolla una programación dirigida a un público selecto, de alta cultura y de corte cosmopolita, como es el caso de los ciclos operísticos, los concursos hípicos, los campeonatos de tenis o las fiestas sociales exclusivas que generan todo un ambiente de "glamour" alrededor de visitantes ilustres o aristocráticos. Esta segunda línea es vívida como lejana al vecindario y dirigida a un público de otro nivel adquisitivo. Como se señalaba en uno de los grupos de discusión: "el otro día fui a la opera regalado por mis hijos porque es carísimo, ninguna persona de la ciudad del bolsillo normal podemos permitirnos" (GD1.13).

Debe añadirse que tanto los eventos masivos como los elitistas presentan extensiones en el resto de la ciudad, como festejos pirotécnicos, actuaciones artísticas en el centro urbano o fiestas de altos vuelos. Las organizadas por Prada en el Mercado Central en 2007 y 2008 tuvieron un amplio impacto popular en un barrio, El Mercat, deslumbrado por los fulgores de la fama y la alta sociedad (Torres y Hernández, 2013).

El área CAC-PD de Valencia podría constituir un buen ejemplo de glolugar, un "proyecto-objeto" que ha colocado a Valencia en la geografía mundial del turismo, el ocio y el entretenimiento. Un símbolo emblemático convertido en "metáfora movilizadora" en la medida que se le ha identificado con "significados positivos...como son la modernidad, el interés público y el futuro" (Cucó, 2013). En esta área, Valencia ha ido transformando una parte de sí misma en una superproducción cultural para el mercado global, lo que progresivamente fue relegando a sus grandes referentes históricos y patrimoniales, ubicados en su viejo centro histórico, hasta entonces centrales en el imaginario de la ciudad (Martí, 2010; Monfort, 2010; Hernàndez y Albert, 2012; Santamarina y Moncusí, 2013).

En el caso de Valencia fue el Centro de Estrategias y Desarrollo (CEyD), puesto en marcha por el Ayuntamiento de Valencia en 2003-2004, el encargado de producir un relato en el que la apuesta por la innovación, la excelencia y la competitividad en el seno de "la Sociedad del conocimiento y la Era Infoglobal", 7 se fiaba casi enteramente a

${ }^{6}$ La Fundación Palau de les Arts Reina Sofía ha sido tan desastrosa que a finales de 2012 tenía una deuda de 24,8 millones de euros.

${ }^{7}$ El CEyD es un organismo de derecho privado sufragado exclusivamente con fondos municipales. Sus expertos, personas cercanas al poder municipal o autonómico, han generado los documentos que han marcado la agenda planificadora y el marketing del proyecto de la Valencia global. 
las instalaciones, propuestas y eventos desarrollados en la CAC-PD. Por ello el CEyD, afirmaba en 2009 que gracias a este glolugar "Valencia se ha situado en el mapa de las grandes urbes. Muestra de ello es su cada vez mayor presencia en los índices y rankings que valoran el posicionamiento de las ciudades más competitivas del mundo". ${ }^{8} \mathrm{Sin}$ embargo, la política de grandes eventos tuvo escasa incidencia en el estímulo de la débil industria cultural valenciana (Requena et al., 2013).

El glolugar CAC-PD presenta el ya referido carácter híbrido entre lugar, no lugar y lugar de memoria. Por esta razón las guías turísticas lo describen con adjetivos como un "complejo único en Europa", "futurista", "colosal”, capaz de atraer a "cientos de miles de turistas". Paralelamente, CEyD, resalta que estos iconos reverdecen el siglo XV, el Siglo de Oro valenciano, pues recuerda el sentido abierto, mediterráneo y emprendedor de Valencia. No faltan las guías que se refieren al complejo CAC-PD como pasaporte para recuperar, en un "salto milenario", la centralidad ostentada hace cinco siglos (Santamarina y Moncusí, 2013).

La orientación glocal del área CAC-PD se advierte en el hecho de que ha conseguido, como hacen los glolugares, colonizar y reelaborar el imaginario local, confiriéndole una nueva sacralidad que, sin emerger de la historia, ha potenciado y revitalizado la identidad local valenciana y cierto orgullo de ciudad, en la medida que los ciudadanos han percibido que el glolugar los rescataba de una suerte de injusto olvido histórico. Todo ello con la ayuda de un contexto económico favorable y la apuesta de las administraciones y del lobby cementero-emprendedor.

El proceso de transformación de la ciudad y sus impactos suscitaba, en 2011, una opinión ambivalente del vecindario. El discurso y la estructura narrativa de los grupos de discusión nos muestra un "carácter bipolar" (Ruiz y Santamarina, 2013). Se destaca que Valencia "ha cambiado muchísimo" (GD2.11), se ha convertido en "una ciudad importantísima" (GD3.11), "hay turismo urbano todo el año" (GD2.11) y se subraya en estos cambios el papel de la CAC. En un segundo tiempo, esa valoración tan positiva es puesta en sordina dado su costo, su distancia respecto al ciudadano de a pie y el despilfarro, cuando no la corrupción inciden otros. La CAC representa una ciudad que, según una vecina entrevistada, "invierte mucho en el turismo, pero no en nosotros, como el transporte, la limpieza" (GD2.11).

Como el resto de glolugares, la zona CAC-PD se halla sometida a una adaptación y revisión continua derivada de los vaivenes del mercado del ocio mundial que le infunde sentido. Mantenerse en esa dinámica competitiva ya no era posible cuando la crisis económica se prolongó como larga y profunda recesión agudizada además por los recortes de gasto público. Así, sin fondos para deslumbrar o simplemente mantenerse, el reclamo global de la zona CAC-PD ha comenzado a diluirse, un declive iniciado en la zona de más reciente incorporación al glolugar, el Puerto Deportivo, ahora medio

\footnotetext{
${ }^{8}$ Valencia, un paso por delante, CEyD, Valencia, 2009.
} 
desmantelado y que se ha quedado sin eventos y sin megayates de lujo. Además, algunos de los más deslumbrantes edificios de la CAC presentan deficiencias estructurales (Palau de les Arts), están inacabados (Ágora), o han perdido el uso continuado y espectacular a que estaban destinados (Palacio de la Ópera, Veles e Vents). Engullidos por la crisis, no pocos de los grandes eventos que allí se celebraban han desaparecido (Fórmula 1, America's Cup, WTV Winters, Campus Party, etc.).

Es significativo que los grupos de discusión realizados en 2013, con los mismos perfiles sociodemográficos que en 2011, mantengan la valoración ambigua pero con bastantes más referencias críticas. La CAC continúa calificándose como "espectacular", se destaca el turismo generado y el grado de notoriedad conseguido por Valencia, pero representa un "modelo que deja olvidados a una gran parte de ciudadanos que no viven en zonas acomodadas" (GD1.13). En una estructura de discurso bipolar, el icono CAC, se contrapone de forma bastante unánime los recortes en la "limpieza viaria de los barrios" (GD2.13), las subidas en el precio del "transporte público... sin ayudas para parados" (GD4.13) o las dificultades de la vida cotidiana. Esta contraposición se nutre, además, de los numerosos casos de corrupción y/o despilfarro vinculados a los grandes eventos muy presentes en la prensa local. Los grandes eventos han contribuido a la generación de una gigantesca deuda pública (29.643 millones de euros, el 29,8\% del PIB valenciano), estrechamente vinculada a la proliferación de redes clientelares (Hernàndez y Albert, 2012) y que, según una estimación reciente, han significado un despilfarro de 12.500 millones de euros de dinero público (Castillo, 2013).

\section{La vida más allá del glolugar Los barrios populares}

En estas dos décadas, las energías, presupuesto y atención del Consistorio se han centrado en los grandes proyectos y eventos, la nueva expansión urbana de clase media y en una política cultural de grandes fastos. Ante estas prioridades, los barrios populares y sus necesidades han sido relegados. La Valencia global es, como otros proyectos neoliberales, una ciudad más fragmentada con un aumento de la desigualdad socio-espacial y de la precariedad urbana (Smith, 1996; Borja y Castells, 1999).

Con la salvedad parcial del metro-tranvía, buena parte de las inversiones en infraestructuras se han orientado a los grandes proyectos y sus servidumbres, a los barrios new build gentrification y, más en general, a generar las condiciones propicias para el desarrollo del negocio inmobiliario. Sin embargo, aún hay escolares en la ciudad de Valencia que acuden a instalaciones provisionales (los llamados "barracones"). Los barrios populares y obreros se han mantenido con los equipamientos conseguidos en la década de los años 80 y hasta mediados de los años 90 (Torres y García, 2013). Junto a ello, se han dado actuaciones puntuales de equipamientos relevantes en estos barrios (como 
el Parque y el Centro Cívico Rambleta, la ampliación-renovación del Polideportivo Nazaret o el Teatro El Musical, en El Cabanyal), en muchos casos como reacción a exigencias históricas. Respecto a la política cultural, baste lo dicho en el apartado anterior.

Además del nivel más general, de ciudad, para captar adecuadamente las iniciativas socio-culturales que nos interesan necesitamos el análisis en el nivel de barrio. Aquí presentamos los barrios de El Mercat y El Carme, como barrios populares centrales, y el barrio de El Cabanyal como barrio obrero periférico. ${ }^{9}$ Como tales barrios populares forman parte, si bien en distinto grado, de la Valencia relegada; sin embargo, estos barrios mantienen un dinamismo, una sociabilidad y unos recursos "a pie de calle", que han constituido una de las bases del surgimiento de acciones socio-culturales de muy diverso tipo.

Para nuestro análisis de estos barrios distinguiremos, siguiendo libremente a Manski (2000) y Blanco y Subirats (2011), entre su "ambiente social", el nivel socioeconómico del vecindario y aspectos sociodemográficos relevantes (mayores, inmigrantes) y a su trama de sociabilidades, y su "marco socio-urbano", conformado por su trama urbana, las viviendas, los equipamientos y servicios con que cuenta el barrio, su ubicación y comunicaciones.

El ambiente social de El Cabanyal remite a un vecindario histórico de pescadores, trabajadores portuarios y agricultores, y uno de los más pobres de Valencia según el Indicador de renta de distritos y barrios del Ayuntamiento y su actualización (Santamarina, 2007; Torres y García, 2013). La histórica homogeneidad de El Cabanyal, socio-económica y cultural, se ha visto complejizada por la presencia en los últimos años de inmigrantes y nuevas formas de pobreza. Junto a los antiguos gitanos residentes, se han instalado gitanos rumanos y otros grupos más o menos marginales, en la parte más degradada del barrio.

Pese a algunas mejoras experimentadas durante las últimas décadas, como la apertura del Paseo Marítimo, la ampliación del tranvía, la habilitación de algunas - escasaszonas verdes y la apertura de una biblioteca pública, El Cabanyal viene claramente a ejemplificar un barrio marginal, periférico (Blanco y Subirats, 2011). Un parque de viviendas de mala calidad, antiguo y con licencias de rehabilitación congeladas por el Ayuntamiento. Un pequeño comercio tradicional muy menguado aunque la presencia del Mercat d'El Cabanyal, el segundo en importancia de la ciudad, contribuya a paliar esa carencia. O bien, la escasez de colegios y centros de enseñanza.

Junto a su carácter popular, otro rasgo histórico de El Cabanyal ha sido su rico asociacionismo vinculado a una densa trama de relaciones vecinales. La vida en la calle sigue siendo valorada por los vecinos, que caracterizan a El Cabanyal como un "pueblo", pese a que la degradación de una parte del barrio, el envejecimiento y los

${ }^{9}$ En el proyecto "Metrópolis glocalizadas: el caso de Valencia", CSO2009-10715, además de la escala de ciudad se trabajó a nivel de barrios, los tres señalados como representativos de la tipología de barrio céntrico popular y barrio periférico obrero, y el barrio de Penya-Roja, construido en los aledaños de la CAC, como representativo del modelo new build gentrification. 
cambios en los estilos de vida, la hayan erosionado. En la actualidad, el barrio cuenta con un potente movimiento vecinal, un entramado festivo alrededor de la Semana Santa Marinera y las Fallas, y distintos tipos de asociaciones recreativas o culturales con el emblemático Ateneo Marítimo. El rechazo a la ampliación de la Avenida Blasco Ibañez generó el surgimiento, hace quince años, de la Plataforma Salvem El Cabanyal, uno de los referentes en Valencia de los nuevos movimientos locales (Cucó, 2008).

Con el nuevo siglo, el Ayuntamiento revitalizó la prolongación de la Avenida Blasco Ibañez hasta el mar para completar el nuevo frente marítimo de la ciudad, con el Paseo Marítimo, el Puerto Deportivo y más al interior la CAC. La prolongación de Blasco Ibañez es un proyecto recurrente en el urbanismo valenciano que supone derruir 1651 viviendas y fracturar el barrio en dos. Además, la trama afectada está declarada como Bien de Interés Cultural. El rechazo al proyecto, desde el barrio y amplios sectores de la ciudad, ha generado un importante movimiento de oposición, más de doce años de movilizaciones y demandas judiciales. Aunque el proyecto se encuentra paralizado por el Tribunal Supremo, el PP local no ha modificado sus planes. Además de apelar a sus sucesivas victorias electorales, el Ayuntamiento ha dejado degradar la parte central del barrio, comprando viviendas, paralizando las actuaciones en ruinas y solares así como la concesión de permisos de rehabilitación y/o mejora a particulares.

La incertidumbre con que se vive en la parte del barrio afectada por la prolongación y la generación de "espacios del miedo", lugares a evitar en el barrio, contrasta con una cultura popular bastante viva, nucleada alrededor de las fiestas, y en los últimos años, el desarrollo de diversas actividades culturales críticas promovidas por Salvem El Cabanyal, que luego se comentará. Este dinamismo contrasta con la desidia municipal que, loas a la Semana Santa aparte, deja desaparecer centros culturales emblemáticos como El Casinet, de origen republicano, o pone trabas a la realización de "Cabanyal. Portes obertes". La única excepción lo constituye la apertura del Teatro El Musical, una iniciativa municipal demandada por los profesionales del teatro en Valencia en conjunción con sectores de vecinos. Hoy, con la crisis, El Musical languidece.

El caso de El Mercat y El Carme presenta tanto similitudes como divergencias respecto a El Cabanyal. Se tratan de dos barrios populares del Centro histórico que han conocido un aumento de su heterogeneidad socio-económica y cultural. Por un lado, la renovación urbana ha supuesto la instalación como vecinos de profesionales y técnicos; por otro lado, en la vivienda más precaria, se han instalado inmigrantes. Además, la presencia de colectivos marginales, que había caracterizado algunos espacios de estos barrios, ha retrocedido con la mejora general, las actuaciones de control y la expulsión de algunos grupos a otros puntos de la ciudad.

El entramado asociativo es también fuerte, especialmente en su vertiente lúdica y festiva, articulado fundamentalmente en torno a las Fallas, y con una fuerte proyección en la calle y otros espacios barriales. En los últimos años, junto a las asociaciones de vecinos se ha consolidado otro tipo de entidades, como Amics del Carme, más re- 
presentativas de los nuevos vecinos profesionales. Aunque en El Carme y El Mercat también se evoca la imagen del barrio como "pueblo" y sus calles presentan un vivo movimiento, la sociabilidad informal que los caracteriza está claramente fragmentada según los distintos tipos de vecinos, tradicionales, profesionales e inmigrantes. Su trama relacional y asociativa conforman un mosaico de pequeños mundos que comparten los espacios y la referencia positiva de su barrio, pero que no se interrelacionan. En los últimos años, se han dado confluencias puntuales en algunas reivindicaciones concretas, unas de carácter patrimonial (como la paralización del PERI de los restos de la Muralla árabe), otras de carácter ciudadano (como la reivindicación del solar del antiguo Teatro Princesa para usos vecinales).

La evolución de los barrios de El Carmen y El Mercat está marcada por el lento proceso de renovación urbana de esta parte del Centro Histórico. Iniciado en los años 80 , ha conocido diversas fases, con la rehabilitación de palacios y casonas y algunas actuaciones integrales, aunque lo predominante han sido las intervenciones puntuales en edificios y la peatonalización de algunas calles. Se trata de un proceso similar al de otros barrios populares centrales de Barcelona, Bilbao o Sevilla, si bien en el caso valenciano se trata de una renovación más limitada y modesta, con carácter menos integral y con menor relevancia en la agenda de la ciudad (Torres y Hernández, 2013). En 1999, el mismo año que el Ayuntamiento redoblaba su apuesta por la CAC, no se renovó el Programa RIVA (de reforma del centro histórico). En los últimos años, se han realizado un par de importantes actuaciones, con fondos europeos, pero aun hoy no se dispone de un plan integral. La escasa relevancia otorgada a la parte popular del Centro Histórico se suele atribuir, por muchos críticos, a la "incultura" de la burguesía valenciana. Sin embargo se suele obviar que la élite política y económica tenía otras opciones de renovación urbana más rentables y más representativas de la nueva Valencia cosmopolita que impulsaba. En términos de acumulación de capital, la renovación del casco histórico es un proceso mucho más largo, costoso y complejo que el beneficio fácil de los grandes proyectos y los nuevos barrios acomodados. En términos simbólicos, el nuevo marketing urbano valenciano se ejemplificaba mejor con la Ciudad de las Artes y de las Ciencias que con el Centro histórico.

El proceso de renovación urbana, aun con sus limitaciones, ha supuesto una clara mejora de buena parte del parque de viviendas de ambos barrios, lo que contrasta con la dinámica de degradación en que se ve sumido El Cabanyal. El barrio de El Mercat, tras la aguda crisis del comercio tradicional de los años 80 , ha recuperado su carácter comercial aunque transformado; por su parte, el barrio de El Carme se ha consolidado como una de las zonas de ocio por excelencia de la ciudad. También en estos barrios populares centrales las carencias en equipamientos son evidentes, y denunciadas con frecuencia por sus vecinos. A la falta de aparcamientos y zonas verdes se suman los déficits en centros educativos, no existe ningún colegio público en El Mercat, y sanitarios, lo que obliga a desplazamientos a los barrios vecinos. Un indicador significativo 
del tipo de terciarización que han conocido estos barrios lo constituyen los equipamientos culturales. En El Mercat y El Carme, aparte de dos importantes museos, el IVAM y el Centre El Carme, sólo existe un equipamiento cultural público -una sala de exposiciones experimental-. Por el contrario, son muy numerosos los centros culturales privados (desde el Circulo de Bellas Artes, la Fundación de Arte Chirivella Soriano, al Centro cultural Octubre), que aunque ubicados en estos barrios se hallan al servicio de sus socios o del conjunto de la ciudad y tienen una escasa incidencia en la vida cotidiana de los vecinos y vecinas de El Mercat o El Carme.

Los ganadores y los perdedores de la Valencia cosmopolita también lo son a nivel imaginario y simbólico. Si la centralidad simbólica la ostenta la Ciudad de las Artes y de las Ciencias, el centro histórico popular ha ocupado un lugar secundario, un atrezzo historicista y patrimonialista como fondo que resaltara la imagen futurista de la CAC y como un recurso turístico más. Por su parte, El Cabanyal o bien no existe para el marketing urbano o bien tiene una imagen negativa, muy deudora de la situación de degradación actual. Así, en un grupo de discusión, un vecino dudaba del atractivo turístico de la fachada marítima "cuando vengan y vean ese Cabanyal tan desestructurado y tan agitanado" (GD1.13).

\section{Iniciativas desde los barrios: la acción socio-cultural alternativa}

La mirada crítica o simplemente distante respecto a la hegemonía del glolugar se ha plasmado en una diversidad de movimientos, acciones e iniciativas que se han dado en Valencia. Nosotros nos centramos en aquellas acciones socio-culturales que, desde los barrios populares o desde sectores profesionales, han reaccionado frente a las políticas culturales del Consistorio o la ausencia de éstas.

Una buena parte de estas iniciativas son anteriores a la crisis económica, si bien la persistencia de ésta, su incidencia social y una nefasta gestión política las han intensificado. Se tratan de acciones socio-culturales e iniciativas culturales trabajadas y puestas en marcha por redes de asociaciones, grupos e iniciativas culturales, algunos con formas organizativas más convencionales y otras más innovadoras.

En general, podemos agrupar estas iniciativas en dos tipos. Por un lado, una respuesta más profesional a la hegemonía cultural de la CAC por parte de determinados sectores creativos (artistas, galeristas, gestores culturales) que, sin ser necesariamente críticos con el modelo cultural urbano hegemónico, desarrollan actividades culturales orientadas al negocio ante los vacíos dejados por una administración pública centrada en la exaltación del glolugar CAC-PD. Y todo ello en el contexto de una situación endémica de debilidad de la industria cultural valenciana. Por otro lado, tenemos una serie de actividades socio-culturales claramente críticas con el modelo neoliberal dominante, en el plano urbano y/o más estrictamente cultural, implementadas por iniciativas ciudadanas 
y vecinales, sin ánimo de lucro y como forma de acción cultural resistente. Como muestra del primer tipo de iniciativas podemos señalar dos bastante paradigmáticas, ubicadas en sendos barrios populares sometidos a procesos de reestructuración y gentrificación: Russafa y El Carme.

En el caso de Russafa, el certamen biánual Russafart, dio sus primeros pasos en 2008, aunque sólo en 2010 adquirió sus rasgos actuales. El certamen, bianual, supone la apertura coordinada durante una semana de galerías de arte, talleres artísticos y pequeños espacios profesionales ubicados en el barrio, para mostrar de manera directa su trabajo, su metodología y su espacio de creación. El certamen pretende promocionar comercialmente la obra de artistas y galerías, situar a Russafa como enclave cultural en la geografía nacional e internacional y activar la vida cultural y creativa del barrio. También debe citarse a Russafa Escènica, que desde 2011 busca ser un evento autogestionado por profesionales teatrales para poder trabajar en unas condiciones laborales inciertas. ${ }^{10}$

Otro caso destacado es el del certamen Ciutat Vella Oberta, inaugurado en 2013, y organizado por un colectivo formado por artistas, galeristas y teóricos del arte unidos por la idea de organizar un festival multidisciplinar en el distrito de Ciutat Vella de Valencia con distintas asociaciones, instituciones y comercios de la zona. Su idea no es muy diferente de Russafart: apoyar al sector profesional del arte y la cultura, revitalizar el panorama artístico de Ciutat Vella, acercarlo a la ciudadanía, visibilizar el arte emergente y afianzar a los consagrados, creando una red entre los diferentes agentes.

El segundo tipo de acciones socio-culturales, claramente de orientación crítica, son más antiguas y presentan una mayor heterogeneidad. Sería el caso, por ejemplo, de los Salvem, nombre genérico que adoptan diversos colectivos y/o coordinadoras cívicas surgidas en oposición a operaciones urbanísticas que suponían la destrucción de entornos urbanos y/o zonas de huerta. Salvem el Botànic fue el primero en surgir a primeros de los años 90 y el pionero, también, en incorporar diversas manifestaciones artísticas en sus campañas y actividades. Además, se establecieron lazos entre urbanistas y profesionales críticos, vecinos afectados y creadores y artistas. Visto el éxito de la fórmula, los posteriores Salvem el Pouet, Salvem l'Horta y Salvem El Cabanyal, al que ya hemos hecho referencia, han desarrollado acciones de reivindicación cultural, como muestras, exposiciones, festivales o certámenes. Un ejemplo entre otros: en 2014 se celebró la décima edición de Cabanyal Portes Obertes, un certamen donde durante una semana diversos artistas muestran sus obras en casas particulares amenazadas por la apertura de la Avenida Blasco Ibañez, como muestra de solidaridad y difusión de la lucha de El Cabanyal.

Con un surgimiento más reciente, tenemos una serie de iniciativas que bien se pueden catalogar como labs, acciones colaborativas, de micromecenazgo y "enclaves

${ }^{10}$ Se trata de una fórmula similar a la utilizada en un nivel autonómico por diversos sectores, como el Col.lectiu de Músics en Valencià Ovidi Montllor, para promocionar la música en valenciano. Ante el abandono por parte de la administración, autonómica y local, se genera un circuito profesional auto organizado para promover comercialmente las propias creaciones (más difícil todavía en la lengua propia). 
culturales". Se trata de una esfera emergente, que se advierte en todo el Estado español, caracterizada por sus planteamientos alternativos a los discursos y políticas culturales habituales, que intentan hacer visible una serie de propuestas y acciones desde la subalternidad y posiciones contra hegemónicas. Se trata, fundamentalmente, de propuestas artísticas de carácter colaborativo, autogestionario y transdisciplinar articuladas en colectivos artísticos con gran vocación de incidencia política y de promoción del procomún (Marín García y Salóm Marco, 2013). Debe observarse que estamos ante prácticas de clasificación esquiva y difusa, que en ocasiones son catalogadas como arte político o arte social. Los miembros de estos colectivos artísticos persiguen un objetivo común, si bien en ocasiones adoptan formaciones inestables y difusas, cambiantes, que se adaptan a las necesidades de cada proyecto específico. En la ciudad de Valencia habría que citar casos como los de Ex-Amics del IVAM, Perifèries, La Calderería, la Ruta del Despilfarro Cultural, Benimaclet Viu, Universitat Lliure de Benimaclet, Desayuno con Viandantes, la Ruta del Despilfarro, los huertos urbanos, las fiestas populares autogestionadas o el portal e-valencia.org. Los temas que nuclean estas alternativas son muy variados: oposición y denuncia al modelo urbano hegemónico; denuncia de la corrupción; generación de micro-espacios alternativos. En estos colectivos suelen mezclarse artistas, sociólogos, arquitectos, activistas sociales y creativos audiovisuales y de las artes escénicas, y desde mayo de 2011 se aprecia la influencia que en ellos están teniendo las ideas y grupos vinculados al 15-M. Como también ha subrayado Caro (2013) estos colectivos pretenden "desapropiar" la cultura, replanteando la relación entre cultura y política y potenciando un nuevo modelo de gestión cultural, más diversa, democrática, colaborativa y crítica. Hasta ahora las instituciones han procurado invisibilizar estas propuestas, pero su difusión en la red, con nuevas prácticas de financiación como el crowdfunding o la fundación de portales de internet de dedicados a la creación de proyectos colaborativos, hace que cada vez más tengan mayor visibilidad e incidencia.

Dentro de este contexto podemos señalar algunos casos muy característicos. El primero sería la proliferación de fiestas populares autogestionadas y alternativas a las oficiales, como la organización de la Foguera de Velluters, que rememora en este barrio de Ciutat Vella un motín obrero de mediados del siglo XIX. Es también el caso de Falles Populars i Combatives, organizadas por diversos colectivos de izquierda anticapitalista e independentista en Benimaclet, el Carme y Velluters, para reivindicar una fiesta crítica y corrosiva con los poderosos y las fuerzas gentrificadoras. También debe citarse la organización vecinal de Festes Populars en barrios como Patraix y Sant Marcel.lí, o el certamen Russafa Cultura Viva, que promueve un Carnaval popular desde 2011 en reivindicación del multiculturalismo y para denunciar la situación de los inmigrantes irregulares. En una línea muy similar está Benimaclet Viu, fundado en 2010, una plataforma creada por diferentes asociaciones, escuelas e institutos del barrio que, entre otras iniciativas, está promoviendo los huertos urbanos en el barrio como medio de revitalización de la agricultura tradicional y ecológica propia de la Huerta de Valencia 
y de reapropiación vecinal del espacio público. Finalmente debe citarse la llamada Ruta del Despilfarro Cultural. Organizada desde 2011 por diversas entidades culturales y ciudadanas, constituye un recorrido por algunos monumentos y espacios de la ciudad de Valencia que pretende "señalar a la ciudadanía los puntos negros de la desidia institucional valenciana" (El País, 11 octubre 2011). Tanto la Ruta del Despilfarro Cultural, como su homóloga la Ruta del Despilfarro centrada en las operaciones urbanísticas, tienen como una de sus etapas centrales la Ciudad de las Artes y de las Ciencias.

Debe enfatizarse que en el funcionamiento y difusión de las iniciativas mencionadas han tenido un papel muy importante las redes sociales virtuales, a través de todo tipo de webs, blogs y plataformas como Facebook, Twitter y Verkami, entre otras. Con todo, hay que destacar que aunque la existencia de estas redes virtuales son vitales para propiciar contactos, favorecer sinergías, tejer alianzas y proyectar mensajes, el mantenimiento de núcleo duro de los activistas, la gestión de iniciativas, o la discusión de estrategias se hace "cara a cara". Más todavía, el apoyo en ciertos barrios de sectores populares poco politizados a estas iniciativas no se deriva tanto de su presencia en la red como de la inserción de sus miembros y activistas en las redes de relaciones y sociabilidad de los barrios. Paradójicamente, algunas de esta iniciativas socio-culturales ciudadanas, ya activadas desde perspectivas profesionales o alternativas, al subrayar y defender la singularidad, autenticidad y genuinidad de determinados espacios o prácticas culturales, corren el riesgo de su posible apropiación mercantilizadora (Harvey, 2013). Valga como ejemplo que la última edición de Russafart estaba patrocinada por una conocida marca de cerveza.

\section{Conclusiones}

En definitiva, podemos extraer diversas conclusiones de nuestro trabajo sobre Valencia, aunque sea con carácter provisional y abierto a nuevas exploraciones y líneas de investigación. En primer lugar, se puede constatar la potente vinculación existente entre el urbanismo neoliberal o empresarial, la política cultural de grandes eventos y proyectos y la apuesta por un modelo de ciudad globalizada de carácter espectacularizador, constituyendo el glolugar el artefacto cultural donde se sintetiza dicha vinculación. Así se ha podido comprobar, en segundo lugar, en el caso de la Ciudad de las Artes y las Ciencias-Puerto Deportivo de Valencia, con los impactos de este glolugar tanto de tipo socio-urbano como de política cultural. En el ámbito socio-urbano la CAC-DP ha constituido la punta de lanza de un urbanismo centrado en los grandes proyectos, los nuevos barrios new bild gentrification y las infraestructuras y equipamientos derivados.

Desde el punto de vista cultural, la CAC-PD ha supuesto tanto una redefinición simbólica y reimaginación cultural y turística de Valencia, relegando su rico patrimonio 
histórico, como una estrategia de política cultural de las elites valencianas, concebida como un motor económico tanto de la ciudad como del conjunto del territorio valenciano. Un hecho realmente a tener en cuenta, puesto que a diferencia de las grandes ciudades globales (Londres, París, Nueva York), que cuentan ya con una nutrida dotación de atractivos culturales, muchos de ellos vanguardistas, en las ciudades medianas como Valencia la activación de un glolugar espectacular y ultramoderno pero disonante del paisaje cultural autóctono, ha supuesto un verdadero impacto mediático, así como todo un revulsivo simbólico en el imaginario local. Si bien la CAC-PD ha suscitado y suscita una valoración positiva, que subraya su impacto en el turismo y la imagen de la ciudad, esta valoración se erosiona por su coste, su lejanía respecto al ciudadano de a pie y el derroche de fondos. La crisis ha mostrado la inviabilidad del modelo y los escándalos de corrupción, algunos con la CAC-PD como espacio protagonista, alimenta esa distancia crítica.

En tercer lugar, las prioridades establecidas por el glolugar CAC-PD y el urbanismo neoliberal valenciano han relegado las necesidades de los barrios populares, de los que aquí hemos abordado los barrios de El Carme y El Mercat, populares centrales, y El Cabanyal, obrero periférico. En general, esta relegación es visible en el estancamiento de sus equipamientos e infraestructuras, con la excepción parcial del metro-tranvía, en el limitado proceso de renovación urbana del centro histórico popular, cuando no en operaciones urbanísticas que pretenden arrasar parte del propio barrio, como en El Cabanyal. Además, estos perdedores lo son también en lo simbólico. En unos casos, el centro histórico popular, por la escasa visibilidad de sus rasgos patrimoniales; en otros casos, con el silencio o la imagen negativa que se adjudica al barrio. Aspectos que los vecinos constatan en sus discursos, enfatizando la lejanía de la ciudad espectacular respecto a su día a día.

Por último, pese a la relegación mencionada, estos y otros barrios populares han conservado una red de sociabilidad, contactos ritualizados y prácticas culturales propias, que han permitido la emergencia de iniciativas socio-culturales alternativas. En algunos casos, ante el vacío de la administración pública se trata de alternativas comerciales, no necesariamente críticas pero presentando unos modelos diferentes al de la Valencia global y la CAC-PD. En otros casos, impulsadas desde colectivos y grupos claramente críticos, estas iniciativas socio-culturales han adoptado diversas formas. En ocasiones de trata de actividades culturales que forman parte de campañas de tipo urbanístico o vecinal. Además, en los últimos años han aumentado las acciones socio-culturales más cercanas a la subalternidad contrahegemónica, desde el ámbito festivo hasta el de la denuncia política. De este modo, el impacto del glolugar promovido por una política cultural y urbanística de corte neoliberal queda contestado por el contrapunto de las emergencias ciudadanas y culturales, que reivindican la reconquista y reconfiguración del espacio urbano desde el punto de vista de las necesidades de sus habitantes. 


\section{Bibliografía}

Alcalá-Santaella, F., F. Díaz de Orueta, X. Ginés y M.L. Lourés (2011): "Valencia", en Subirats, J, Martí-Costa, M, Iglesias, M y Tomàs, M, (eds.): Políticas urbanas en España. Grandes ciudades, actores, gobiernos locales. Barcelona, Icaria, pp. 201-227.

Bellet, C. (2013): “¿De lo glocal a lo globanal? Las ciudades intermedias en los tiempos de la globalización, en Cucó, J (ed.): Metamorfosis urbanas. Ciudades españolas en la dinámica global, Barcelona, Icaria, pp. 23-50.

Brenner, N. \& N. Theodore (2002): "Cities ant the Geographies of Actually Existing Neoliberalism", en Spaces of Neoliberalism: Urban Restructuring in North America and Western Europe, Oxford, Blackwell Publishers, pp. 2-32.

Blanco, I. y J. Subirats (2011): "Exclusión social, territorio y políticas urbanas en España: una mirada comparativa", en M. Iglesias et al. (eds), Politicas urbanas en España. Grandes ciudades, actores y gobiernos locales, Barcelona, Icaria, pp. 335-362.

BoIRA, J.V. (2012): Valencia, la tormenta perfecta. Barcelona, BA.

Borja, J. y M. CAstells (1999): Local y global. La gestión de las ciudades en la era de la información, Madrid, Taurus.

CAro, E. (2013): "Trazando la curva de una gestión cultural diversa" I Congreso Anual de Investigadores en Arte, Universidad de Valencia, Valencia.

Castillo, S. (2013): Tierra de saqueo. La trama valenciana de Gürtel, Barcelona, Lectio Ediciones.

Cucó, J. (2008): “Sociabilidades urbanas”, Ankulegui, 12, pp. 65-82.

Cucó, J. (2013): "Poniendo a Valencia en el mapa global. Políticas, desarrollos urbanos y narrativas sobre la ciudad", en CUCÓ, J (ed.): Metamorfosis urbanas. Ciudades españolas en la dinámica global, Barcelona, Icaria, pp. 157-179.

DíAz Orueta, F. (2013): "Sociedad, espacio y crisis en la ciudad neoliberal”, en Cucó, Josepa (ed), Metamorfosis urbanas. Ciudades españolas en la dinámica global, Barcelona, Icaria,

GAJA, F. (2008): “El 'tsunami urbanizador' en el litoral mediterráneo”. El ciclo de hiperproducción inmobiliaria 1996-2006”, Scripta Nova, p. 270

GAJA, F. (2013): “Cui prodest? Grandes eventos/grandes proyectos. Una apuesta perdida”, en Cucó, Josepa (ed.): Metamorfosis urbanas. Ciudades españolas en la dinámica global, Barcelona, Icaria, pp. 201-228.

Harvey, D. (1989): "From managerialism to entrepreneurialism: The transformation in urban governance in late capitalism", Geografiska Annaler, 71-B, pp. 3-7.

Harvey, D. (2013): Ciudades rebeldes. Del derecho de la ciudad a la revolución urbana, Madrid, Akal. 
HernÀndez, G.-M. (2012): La condición global. Hacia una sociología de la globalización . Valencia, Obrapropia.

HernÀndez, G.-M. (2013): “Glolugares: espacios singulares de la glocalización”, Kamchatka, 2, pp. 13-36.

Hernàndez, G.-M. y M. Albert (2012): "La dinámica de la política cultural en el País Valenciano: posiciones, discursos y prácticas de los actores culturales valencianos", Revista de Investigaciones Políticas y Sociológicas, vol. 11, 3, pp. 81-114.

HernÀndez, G.-M., et al. (2014): La cultura como trinchera. La política cultural en el País Valenciano (1975-2013), Valencia, Publicacions de la Universitat de València.

Manski, Ch. (2000): "Economic Analysis of Social Interactions", The Journal of Economic Perspectives, pp. 14- 3 y 115-136.

Marín García, T. y E. Salóm Marco (2013): "Los colectivos artísticos: microcosmos y motor de la promoción de las artes", Teknokultura. Revista Digital de Movimientos Sociales, vol.10, 1, pp. 49-79.

Martí, J. (2010): “Turismo y museos en la ciudad de Valencia”, en Arrieta, I (ed.): Museos y parques naturales: comunidades locales, administraciones públicas y patrimonialización de la cultura y la naturaleza, Bilbao. Universidad del País Vasco, pp. 63-90.

Monfort, V. (2010): "Valencia: turismo cubista", en Sorribes, J (ed): Valencia, 1957-2007. De la riada a la Copa del América, Valencia, Publicacions de la Universitat de València, pp. 101-15.

Prieto, E. (2011): La arquitectura de la ciudad global. Redes, no-lugares, naturaleza, Madrid, Biblioteca Nueva.

Requena Mora, M. et al. (2012): “L’impacte de les polítiques culturals en la indústria cultural del País Valencià”, VIè Congrés Català Internacional de Sociologia.

Ruiz, M. y B. SAntamarina (2013): "La Valencia bipolar y trepidante. Discursos y representaciones sobre la transformación urbana" en Cucó, Josepa (ed). La ciudad pervertida. Una mirada sobre la Valencia global, Barcelona, Anthropos, pp. 117-140.

Santamarina, B. (dir.) (2007): Hijos del mar, hijos de la tierra. Historias de vida del Cabanyal-Canyamelar, Valencia, Reproexpres.

Santamarina, B. y A. Moncusí (2013): "Manifiestos y latencias en la Valencia de las guías turísticas”, en Cucó, Josepa (ed.): Metamorfosis urbanas. Ciudades españolas en la dinámica global, Barcelona, Icaria, pp. 259-283.

Sassen, S. (2001): The Global City. Princeton, Princeton University Press.

Sмiтн, N. (1996): The new urban frontier: gentrification and the revanchist city, London, Routledge.

Swynegedouw, E., F. Moulart y A. Rodriguez (2002): "Neoliberal urbanization in Europe: Large-Scale Urban Development Projets and the New urban Policy", Antipode, vol 34. 
Torres, F. y G-M. Hernàndez (2013): "Estar en el mapa tenía un precio. El Centro Histórico popular en la Valencia glocalizada. Los barrios de El Mercat y El Carme", en Cucó, Josepa (ed.): Metamorfosis urbanas. Ciudades españolas en la dinámica global, Barcelona, Icaria, pp. 377-399.

Torres, F. y P. García Pilan (2013): "La ciudad fragmentada. Análisis comparativo de cuatro barrios emblemáticos", en Cucó, Josepa (ed). La ciudad pervertida. Una mirada sobre la Valencia global, Barcelona, Anthropos, pp. 163-188.

Tudela, A (2014): Crisis, S.A. El saqueo neoliberal, Madrid, Akal. 